\title{
Progress and Prospect of Research on Error System
}

\author{
Zheng-Wei Cheng, Jin-Ge Zhou, Kai-Zhong Guo
}

Research Institute of System Engineering, Guangdong University of Technology, Guangzhou, China.

Email: alvis201314@126.com

Received April 2 $2^{\text {nd }}, 2013$; revised May 20 ${ }^{\text {th }}$ 2013; accepted June 25 $5^{\text {th }}, 2013$

Copyright (C) 2013 Zheng-Wei Cheng et al. This is an open access article distributed under the Creative Commons Attribution License, which permits unrestricted use, distribution, and reproduction in any medium, provided the original work is properly cited.

\begin{abstract}
The purpose of this paper is to study the error system progress and prospects. It presents the background, motivation and status quo of the theory of error system through review form and focuses on the mathematical structure of the error system, the methodology and tool used for doing research on this theory and made a forward-looking introduction to the research direction and practical application of this theory, pointing out that the theoretical depth and practical application of a huge space, so as to provide a reference for related researchers.
\end{abstract}

Keywords: Error; Error System; System Structure

\section{Introduction}

Systems are made up of interrelated elements, interaction with a specific structure and function of organic whole $[1,2]$. The main feature of system science is holistic and comprehensive. With the development of society, the progress of science and technology, the social material production gradually intensification and specialization, the complexity of the system increases day by day. Since the nineteen forties system science quickly developed into an interdisciplinary science field, each field attempts from the system point of view to study the internal and external environment and interaction problems.

In the real world, errors are everywhere. Both the social system and natural system, whether it is scientific research or social practice, will meet or appear a variety of errors without exception. As global warming is due to human excessive emissions of carbon dioxide, methane and other greenhouse gases, if not timely take effective measures to curb human behavior, the earth system will face many ecological disasters, such as sea level rise, serious desertification, more frequent flooding and other disasters like these.

Through the theory and practice of system engineering, system structure determines the system behavior. If decision makers change the existing structure of the system through the appropriate decision making and policy, and error-prone system caused the error, the fundamental structure of the loss and disaster would cease to exist and a variety of incentives to intervene before the error occurred, and thus avoid their occurrence. We adopt the qualitative and quantitative methods to study the system containing the wrong tendency and find out the wrong part of structure improvement.

In any system, due to the dynamic development of themselves and their environment, resulting in an error in the system also in a dynamic development coupled between the various subsystems within the system, and the linkages between the various components of the interaction, the study of error system becomes more complicated. Starting from the Error-Avoiding \& Error-Eliminating theory perspective, we need to make new adjustment according to the changes in the system to avoid and eliminate error. Because of the complex and volatile nature of the error system, we need further research and discussion.

\section{Literature Review}

\subsection{Study of General Systems Theory [2-6]}

In the 1940s, Austrian-American theoretical biologist L. $\mathrm{V}$. Bertalanffy proposed general systems theory. The theory is based on the principles and laws of nature and all existing social system as the research object to study different systems obey common general system of principles and laws. In 1946, American scholar P. M. Morse and G. E. Kimball wrote the book "The Methods of Operations"; In 1948, the American scientist Norbert Wiener wrote "Cybernetics or Control and Communication in the Anima and the Machine"; That same year, C. E. Shannon wrote "Mathematical and Found of Communication", which marks that system discipline of opera- 
tions research, system control and system of information theory as a discipline was born.

After the Second World War, the quantitative method with the electronic computer which was widely used to large complex systems in the field of engineering, at the same time, economic and social problems was analyzed. Once obtained the mathematical expression and computing tools, system thinking and methods from a philosophical thinking become specialized subject-system engineering. In the 1970s and 1980s, they results in a system of self-organization theory. In 1969, Belgian physical chemist I. Prigogine proposed the Dissipative Structure Theory and at the same time, the German physicist $\mathrm{H}$. Haken proposed Synergetics. This theory answers system automatically to orderly structure from the macro, micro, and the link between the two. The results are known as the theory of self-organization. In the 1970s, some theories are of great significance to the development of system science. German scientists M. Eigen absorbed the Theory of Evolution thought and Self-organization Theory, and in 1979 he put forward Super Circulation Theory and interpreted the origin of life as a self-organizing phenomenon and put forward the self-organization principle of nature evolution. French mathematican R. Thom in 1972 published a "Stabilité structurelle et morphogenèse", and its theory of mutation phenomenon made the system of the profound elaboration, created Catastrophe Theory.

Since the 1980s, the rise of Nonlinear Science and Complexity study has played a very positive role in promoting the development of systems science. The rise of the international academic study of complexity, a prominent sign for the purpose to study the complexity of the Santa Fe Institute (SFI) was established in 1984 in the capital of Santa Fe, New Mexico, USA. SFI submitted: adaptability to create complexity. They focus on the study of Complex Adaptive System (CAS), and developed a system software platform of SWARM.

In early 1990, the Chinese scholar such as Qian Xuesen first dealt with the open complex giant system named from qualitative to quantitative integration method. This approach to the computer, networking and communications technologies, artificial intelligence, knowledge engineering and other high-tech issues problems is put forward. Comprehensive integration methodology is to consider and resolve the overall problem. Qian Xuesen pointed out that this method was different from the Bacon reductionist method of modern science has been in use, is a leap forward in understanding the methodology under conditions of modern science.

\subsection{Study of Error System Theory}

Since the 1980s, China's systems engineering scholar,
Professor Kai-Zhong Guo in-depth analysis of errors based on a combination of qualitative and quantitative integration error quantification wrong relationship with the study of mathematical tools and logic tools, as well as the error causes and mechanisms, transmission and conversion methods and laws, to predict and eliminate the wrong way to do a preliminary study. Has completed the "Get Rid of The Wrong School Cited Theory”, "The Discriminate Corporate Fixed Assets Investment Decisions Wrong Theory and Methods”, "Large Complex System Conflicts and Errors Theoretical Methods and Applications", "Error Set Theory", "The Error Logic", "Error System" the monograph, published more than 100 papers at home and abroad on the basis of Error-Avoiding \& Error-Eliminating Theory, especially application of the theory in the area of decision-making method research on the subject, making the five Chinese original artificial intelligence theory the one Error-Avoiding \& Error Eliminating Theory further developed, but also to promote the development of the Error System Theory.

\section{Research on Structure of Errors System [7-11]}

To clearly study the system error causes and mechanisms, delivery and transformation methods and rules, you have to research the error in the system, in terms of time or space between all the elements of the organic connection and interaction way or order, namely the structure of error system.

Define 3.1. Problem set Conditions $T_{i j}$, Conclusion $J$, Intrinsic functio $G Y$ Purpose function $M G$, Established in accordance with certain relationships (structure) $R_{i j}$ constitute a system called an object system (when it is not misleading, is also referred to as system) is recorded as $X=x\left(\{w\}, T_{i j}, J, G Y, M G, R_{i j}\right)$.

Define 3.2. In the object system, if the factors that constitute it have at least one is wrong, then call an error system.

Define 3.3. $s_{n}$ refers to a error system; $e_{n}$ is an element of the error system.

\subsection{Series Structure of the Error System}

Series structure refers to the errors in the system as a pair of associated elements satisfaction and only one-way full compliance, as shown in Figure 1, described mathematically as follows:

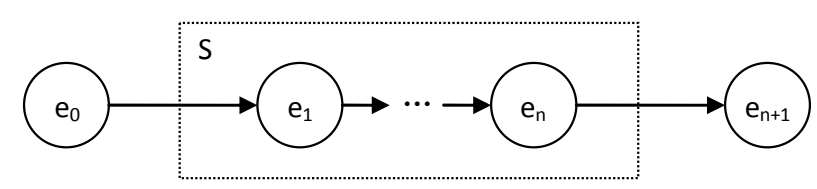

Figure 1. Series structure diagram. 


$$
\left\{\begin{array}{c}
s_{1}=\phi_{0}\left(s_{0}, R_{01}\right) \\
s_{2}=\phi_{1}\left(s_{1}, R_{12}\right) \\
\vdots \\
s_{n+1}=\phi_{n}\left(s_{n}, R_{n, n+1}\right)
\end{array}\right.
$$

Can be obtained by (1):

$$
s_{n+1}=\phi_{n}\left(\phi_{n-1}\left(\cdots \phi_{1}\left(\phi_{0}\left(s_{0}, R_{01}\right), R_{12}\right), \cdots, R_{n-1, n}\right), R_{n, n+1}\right)
$$

\subsection{Parallel Structure of the Error System}

If every element within the system $e_{0}$ rely on input nodes, each element of the output node compliance within the system, and are mutually independent relationship between elements within the system, the structure of the system known as parallel structure, as shown in Figure 2, described mathematically as follow:

$$
\left\{\begin{array}{c}
s_{1}=\phi_{0}\left(s_{0}, R_{01}\right) \\
\vdots \\
s_{n}=\phi_{n-1}\left(s_{0}, R_{0, n-1}\right) \\
s_{n+1}=\phi_{n}\left(s_{1}, \cdots, s_{n}, R_{1, n+1}, \cdots, R_{n, n+1}\right)
\end{array}\right.
$$

Can be obtained by (3):

$$
s_{n+1}=\phi_{n}\left(\phi_{0}\left(s_{0}, R_{01}\right), \cdots, \phi_{n-1}\left(s_{0}, R_{0, n-1}\right), R_{1, n+1}, \cdots, R_{n, n+1}\right)
$$

\subsection{Feedback Structure of the Error System}

If the system has one and only an element of compliance the input node $e_{0}$, output node compliance and only compliance in another element, and all elements of a relationship ring known as the feedback structure, the structure of the system, as shown in Figure 3, described mathematically as follows:

$$
\left\{\begin{array}{c}
s_{1}=\phi_{0}\left(s_{0}, s_{n}, R_{01}\right) \\
s_{2}=\phi_{1}\left(s_{1}, R_{12}\right) \\
\vdots \\
s_{k}=\phi_{k-1}\left(s_{k-1}, R_{k-1, k}\right) \\
s_{k+1}=\phi_{k}\left(s_{k}, R_{k, k+1}\right) \\
\vdots \\
s_{n}=\phi_{n-1}\left(s_{n-1}, R_{n-1, n}\right) \\
s_{n+1}=\phi_{n}\left(s_{k}, R_{k, n+1}\right)
\end{array}\right.
$$

Can be obtained by (5):

$$
s_{n+1}=\varphi_{n}\left(\varphi_{k-1}\left(\varphi_{k-2}\left(\cdots \varphi_{1}\left(\varphi_{0}\left(s_{0}, s_{n} R_{01}\right), R_{12}\right), \cdots,\right) R_{k-1, k}\right), R_{k, n+1}\right)
$$

\subsection{Expansion Shrinkage Structure of the Error System}

\section{(1) Radiation Type Structure}

If the system has one and only one element of compliance at the input node $e_{0}$, and the remaining elements of the system with respect to the elements of the input to the competitive relationship, the structure of the system is called radiation type relative to the output node $e_{n+1}$ export partnership structure, as shown in Figure 4(a), described mathematically as follows:

$$
\left\{\begin{array}{c}
s_{1}=\phi_{0}\left(s_{0}, R_{01}\right) \\
s_{2}=\phi_{1}\left(s_{1}, R_{12}\right) \\
\vdots \\
s_{n}=\phi_{n-1}\left(s_{1}, R_{1, n}\right) \\
s_{n+1}=\phi_{n}\left(s_{2}, \cdots, s_{n}, R_{2, n+1}, \cdots, R_{n, n+1}\right)
\end{array}\right.
$$

Can be obtained by (7):

$$
s_{n+1}=\varphi_{n}\left(\varphi_{1}\left(\varphi_{0}\left(s_{0}, R_{0,1}\right), R_{1,2}\right), \cdots, \varphi_{n-1}\left(\varphi_{0}\left(s_{0}, R_{0,1}\right), R_{1, n}\right), R_{2, n+1}, \cdots, R_{n, n+1}\right)
$$

\section{(2) The Contraction-Type Structure}

If the system output node $e_{n+1}$ compliance and only one element of compliance within the system, and the remaining elements of the system with respect to the elements of the export partnership, enter the competitive relationship relative to the input node $e_{0}$, the structure of the system is called contraction-type structure, as shown in Figure 4(b), described mathematically as follows:

$$
\left\{\begin{array}{c}
s_{1}=\phi_{0}\left(s_{0}, R_{0,1}\right) \\
\vdots \\
s_{n-1}=\phi_{n-2}\left(s_{0}, R_{0, n-1}\right) \\
s_{n}=\phi_{n-1}\left(s_{1}, \cdots, s_{n-1}, R_{1, n}, \cdots, R_{n-1, n}\right) \\
s_{n+1}=\phi_{n}\left(s_{n}, R_{n, n+1}\right)
\end{array}\right.
$$

Can be obtained by (9):

$$
s_{n+1}=\varphi_{n}\left(\varphi_{n-1}\left(\varphi_{0}\left(s_{0}, R_{0,1}\right), \cdots, \varphi_{n-2}\left(s_{0}, R_{0, n-1}\right), R_{1, n}, \cdots, R_{n-1, n}\right) R_{n, n+1}\right)
$$




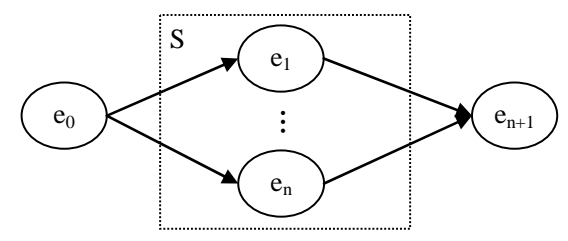

Figure 2. Parallel structure diagram.

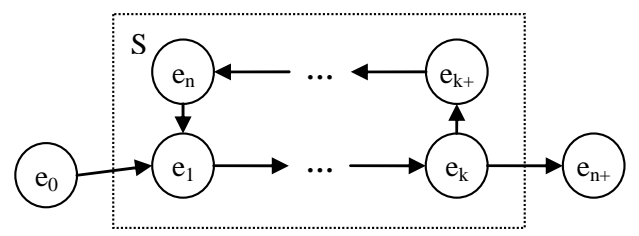

Figure 3. Feedback structure diagram.

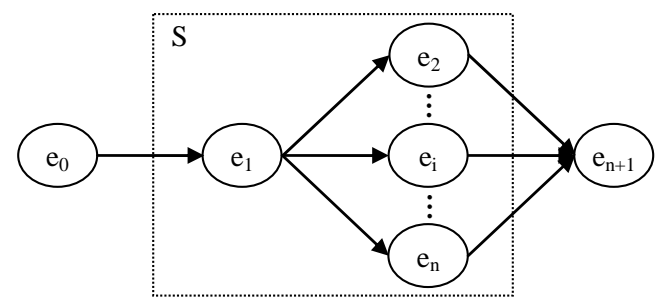

(a)

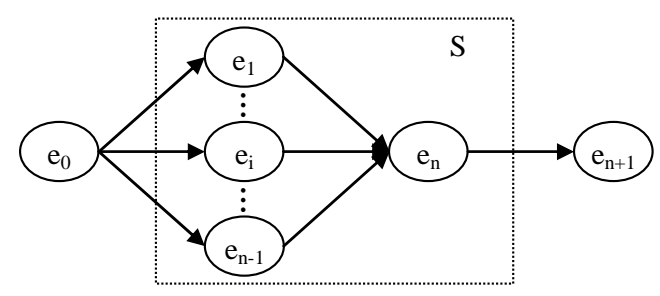

(b)

Figure 4. (a) Radiation type structure diagram; (b) Contraction-type structure diagram.

\subsection{Contains Structure of the Error System}

If the system has only one node in compliance with the input node $e_{0}$. The elements meet certain conditions with respect to the output node $e_{n+1}$, contains the rest of the nodes within the system, the structure of the system known as the implication structure, as shown in Figure 5, described mathematically as follows:

$$
\left\{\begin{array}{c}
s_{1}=\phi_{0}\left(s_{0}, R_{0,1}\right) \\
s_{1} \Rightarrow\left(T_{12}\right) s_{2} \\
\vdots \\
s_{1} \Rightarrow\left(T_{1, n}\right) s_{n} \\
s_{2} \Rightarrow\left(T_{23}\right) s_{3} \\
\vdots \\
s_{n-1} \Rightarrow\left(T_{n-1, n}\right) s_{n} \\
s_{n+1}=\phi_{n}\left(s_{1}, \cdots, s_{k}, R_{1, n+1}, \cdots, R_{k, n+1}\right)
\end{array}\right.
$$

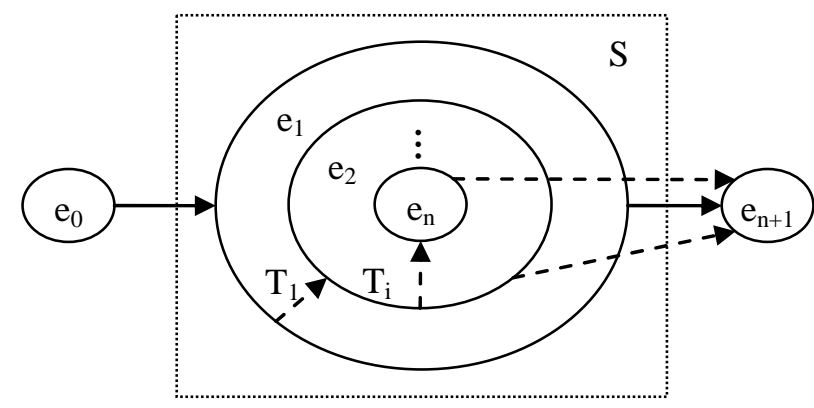

Figure 5. Contains structure diagram.

Formula (11) $s_{k}$ quantity to meet the condition number is equal to satisfy several conditions, there are several states of the corresponding elements jointly determine the state of the output node.

\section{Research Prospect of the Error System}

\subsection{Theoretical Outlook of the Error System}

For any system, it should be based on existing theories and tools for its study on the system structure. First, the study on how to define an error system or a boundary with error-prone system, comparing it with the General System (non-errors or erroneous trend system) structural similarities, finding an error within a system of variables and exogenous variables. Secondly, based on the structure of the system, we can use different theories and tools for research. We can use chaos theory [12] to study the complex currently unable to understand its structure system and the Gray Theory [13] can be studied to have some knowledge of the system structure or its part system, general network theory error-prone network analysis [14] and to use the compartment model or an agentbased model [15], or a combination of the model of dynamic error-prone system modeling and simulation. Finally, the study has an error-prone system and needs to explore such systems of linear and nonlinear [16], and they are the relationship between structures and explore the uncertainty of the research process itself which was introduced in the modeling uncertainties and by the uncertainty generated by the unknown interference. The study contains more error-prone system as this combination is often an error-prone system generating an error when, directly or indirectly affect the other has an errorprone system, or their mutual impact, resulting in largescale error and a huge loss.

\subsection{Application Prospect of Error System}

For the practical application of the error system, there are three main aspects: First, the establishment of the error system case database. Collected and classified in accordance with the respective areas and features of the error system case. Case database error system can provide de- 
cision support for policy makers and managers. Second, use existing data and tools to build error-proofing and eliminate error system. Existing modeling and simulation tools of Matlab, Vensim, and the Any Logic software build error proofing and eliminate the error system, and system structure integrated or embedded into existing decision support system which has the error data; You can also take advantage of to build complex the neural network model, through continuous training and learning, this model of similar errors in judgment and given the decision-making. Third, building modeling and simulation software for the error system research. Accumulated some experience in applied research, you can take advantage of the known data, analysis results and existing error-proofing and eliminate error system modeling and simulation software to build specifically for the error system research.

\section{Conclusion}

We introduce error system based on the research background and motivation, an overview of the theoretical study of the status quo, and focus on the structure of the error system, the theory prospected future theoretical research and application, and may be used the methods and tools to make elaborate. Of course, in the actual course of the study, the researchers may encounter a lot of new problems, and challenges might be now put forward the theory, which are inevitable, because any one error and error-prone system are constantly changing. Researchers also continue to improve the level of research. Nevertheless, we can still provide theoretical reference for scholars to study the error system and just enter the erroneous theory research staff.

\section{REFERENCES}

[1] G. R. Zeng and K. J. Yi, "Cybernetic Information Theory of Systems Theory and Philosophy,” Central South University of Technology Press, Changsha, 1988.
[2] Y. L. Wang, “Systems Engineering,” China Machine Press, Beijing, 2008.

[3] Z. T. Wang, "An Introduction to Systems Engineering," Electronics Industry Press, Beijing, 2006.

[4] D. C. Sun, "An Introduction to Systems Engineering," Tsinghua University Press, Beijing, 2004.

[5] F. Y. Lin and J. Z. Wu, "General System Theory and Its Application,” Journal of Systems Engineering, Vol. 12, No. 3, 1997, pp. 21-27.

[6] L. V. Bertalanffy, "General System Theory-Foundation, Development, Applications (Revision Edition),” George Beaziller, Inc, 1973.

[7] K. Z. Guo and S. Q. Zhang, "An Introduction to Eliminate Error,” South China University of Technology Press, Guangzhou, 1995.

[8] K. Z. Guo, “Error System,” Science Press, Beijing, 2012.

[9] K. Z. Guo, “Error Logic,” Science Press, Beijing, 2008.

[10] Y. G. Bian and K. Z. Guo, "Mathematical Definition of the Basic Structure of Enterprise Management System," The Practice and Understanding of Mathematics, Vol. 41, No. 18, 2011, pp. 104-111.

[11] H. O. Xiong, J. Song and K. Z. Guo, "Study on Error System Rules," Statistics and Decision Making, No. 3, 2009, pp. 41-43.

[12] S. Ionita, “A Chaos Theory Perspective on System’s Failure,” Information Sciences, Vol. 127, No. 3, 2000, pp. 193-215. doi:10.1016/S0020-0255(00)00037-2

[13] T. Y. Pai and K. Hanaki, "Using Grey System Theory to Evaluate Transportation Effects on Air Quality Trends in Japan,” Transportation Research Part D, Vol. 12, No. 10, 2007, pp. 158-166. doi:10.1016/j.trd.2007.01.007

[14] S. P. Borgatti, A. Mehra and D. J. Brsss, "Network Analysis in the Social Sciences,” Science, Vol. 323, No. 5916, 2009, pp. 892-895. doi:10.1126/science.1165821

[15] R. Axelrod, "The Complexity of Cooperation: Agent Based Models of Competition and Collaboration,” Princeton University Press, Princeton, 1997.

[16] Z. Cai and C. L. Tsal, "Diagnostics for Nonlinearity in Generalized Linear Models,” Computationgal Statistics \& Data Analysis, Vol. 29, No. 3, 1999, pp. 445-469. doi:10.1016/S0167-9473(98)00079-6 